Correction

\title{
Correction: Deciphering the role of nuclear and cytoplasmic IKKa in skin cancer
}

\author{
Josefa P. Alameda, Miriam Gaspar, Ángel Ramírez, Manuel Navarro, Angustias \\ Page, Cristian Suárez-Cabrera, M. Guadalupe Fernández, Jose R. Mérida, Jesús \\ M. Paramio, Rosa A. García-Fernández, M. Jesús Fernández-Aceñero, M. Llanos \\ Casanova
}

Copyright: Alameda et al. This is an open-access article distributed under the terms of the Creative Commons Attribution License 3.0 (CC BY 3.0), which permits unrestricted use, distribution, and reproduction in any medium, provided the original author and source are credited.

Present: The grant support information is incomplete.

Correct: The complete grant support is as follows.

Original article: Oncotarget. 2016; 7:29531-29547. https://doi.org/10.18632/oncotarget.8792

\section{FUNDING}

This research was supported partially by funds from Fondo Europeo de Desarrollo Regional (FEDER) and by grants from the Ministry of Economy and Competitiveness of Spain (PI13/02580 and PI14/01403, from the Instituto de Salud Carlos III to M.L. Casanova and A. Ramírez respectively) and by grants 1.010 .511 (Fundación Banco de Santander-Universidad Alfonso X el Sabio) to M.J Fernández-Aceñero; Comunidad Autónoma de Madrid grant S2010/BMD-2470 (Oncocycle Program) and CIEM13-4E-1944 to JMP; AES grants ISCIII-RETIC RD06/0020/0029 and RD12/0036/0009 to JMP. 